\title{
CONCEITO DE SISTEMAS HIDROLÓGICOS LÊNTICOS NATURAIS E SUAS ESCASSAZ DIFERENCIAÇÕES NA LITERATURA BRASILEIRA
}

\author{
Denivaldo Ferreira de Souza ${ }^{1}$
}

\section{RESUMO}

O presente trabalho busca em sua introdução apresentar um breve enfoque sobre os sistemas hídricos presentes nos continentes e dar destaque a relação que de InPut, InTake e OutPut que Christofoletti (1979) aborda. No decorrer, são expostos embasamentos teóricos e empíricos sobre sistema hidrológicos lênticos naturais relacionados a suas definições que ainda são pobres na literatura brasileira. Assim sendo, conclui-se de maneira pessoal a necessidade de trabalhos aprofundados sobre a limnologia em caráter de definições e classificações de ambientes lacustres para que o meio acadêmico utilizam-se de referencia em seus estudos.

PALAVRAS-CHAVE: Sistemas lênticos; Lagos; Lagoas.

\section{CONCEPT OF SYSTEMS NATURAL HYDROLOGIC LENTIC AND YOUR ESCASSAZ DIFFERENTIOTIONS IN BRAZILIAN LITERATURE}

\section{ABSTRACT}

This study aims to present a brief introduction its focus on water systems present in the continents and highlight the relationship of input, intake and OutPut that Christofoletti (1979) addresses. Throughout, theoretical and empirical studies of natural lentic hydrological system related to their definitions that are still poor in Brazilian literature soffits are exposed. Therefore, it is concluded in a personal way the need for extensive work on the limnology in character definitions and classifications for water bodies that are used academic reference in their studies.

KEY-WORDS: Lentic systems; Lakes; ponds.

\footnotetext{
${ }^{1}$ Geógrafo, mestrando em Geografia pela Universidade Federal de Mato Grosso do Sul/UFMS, campus de Três Lagoas. E-mail deny1609@gmail.com
} 


\section{CONCEPTO DE SISTEMAS NATURAL HIDROLÓGICOS LENTICAS Y SU ESCASSAZ DIFERENCIACIONES EN LITERATURA BRASILEÑA}

\section{RESUMEN}

Este estudio tiene como objetivo presentar una breve introducción de su enfoque en los sistemas de agua presentes en los continentes y poner de relieve la relación de entrada, admisión y de salida que Christofoletti (1979) direcciones. En todo momento, se exponen los estudios teóricos y empíricos del sistema hidrológico lénticos naturales relacionados con sus definiciones que siguen siendo pobres en plafones literatura brasileña. Por lo tanto, se concluye de un modo personal la necesidad de una amplia labor en la limnología en las definiciones y clasificaciones de caracteres para los cuerpos de agua que se utilizan de referencia académica en sus estudios.

PALABRAS-CLAVE: Sistema Lenticas; Lagunas; Estanques.

\section{INTRODUÇÃO}

Há anos, pessoas perceberam que há coisas comuns nas diferentes áreas do conhecimento. Existem problemas similares que podem ser resolvidos com soluções similares. Estas mesmas pessoas perceberam que algumas características e regras aconteciam em todas as áreas. Assim, surgiu à definição de Sistema, um conjunto de elementos inter-relacionados com um objetivo comum. Isto quer dizer que todas as áreas do conhecimento possuem sistemas. $E$ que os sistemas possuem características e leis independentemente da área onde se encontram (CHIAVENATO, 2004).

A compreensão de sistemas pode ser como um conjunto de elementos ligados entre si por relações de forma a constituir uma organização, ou ainda "exteriormente" o todo organizado, relacionando-se com o meio exterior, então este é sujeito a mudanças, e que ainda pode apresentar em qualquer momento um modo determinado de ação ou comportamento (MACIEL, 1974 apud IZIPPATO, 2013).

Considerando que os sistemas funcionam executando processos, visando obter determinadas respostas, Thornes \& Brunsden (1977 apud CHRISTOFOLETTI, 1979 , p.10) "definem o sistema como conjuntos de objetos ou atributos de suas relações, que se encontram organizados para executar uma função particular." Dessa forma, dentro desse conceito, o sistema é um operador que em um determinado lapso 
de tempo recebe a entrada (input), há as interações (intake) e o transforma em saída (output), Figura 1.

Figura 1: Representação esquemática de um sistema, assinalando as partes componentes.

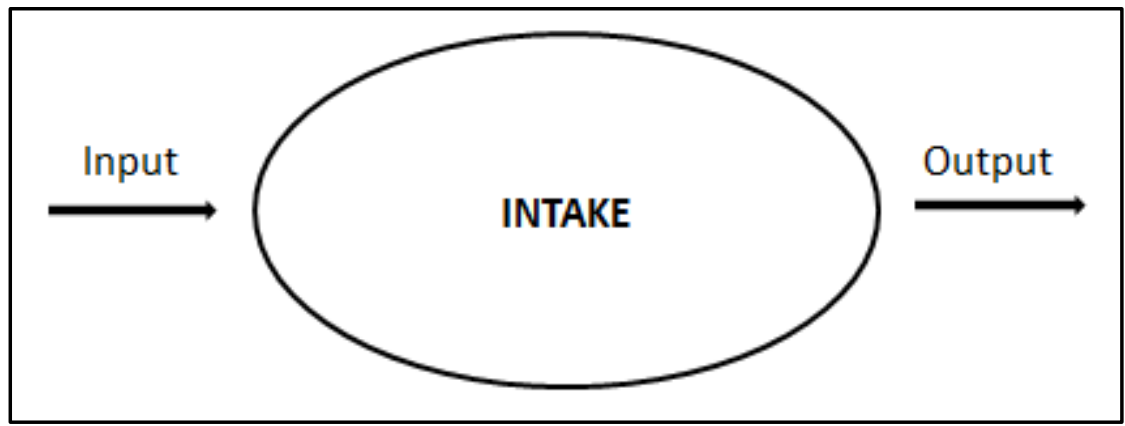

Fonte: adaptado de Christofolletti (1979).

Baseando-se nessas definições se pressupõe, inicialmente, que os sistemas devem ter suas partes componentes, denominadas unidades, ou, ainda, elementos, as quais devem encontrar-se inter-relacionadas, dependentes umas das outras, através de ligações que denunciam os fluxos.

Em Christofolletti (1999) ainda discute-se que é de conhecimento a existência de sistemas complexos, na evolução da matéria (sistemas físicos), na evolução dos seres vivos (sistemas biológicos), na evolução da sociedade (sistemas sociais), na economia (sistemas econômicos) e também sistemas mais complexos, como o das organizações espaciais (sistemas geográficos).

Os sistemas geográficos devido à característica de seus subconjuntos apresentam sistemas ainda menores e mais complexos, tais como: sistemas ambientais físicos (geossistemas), os sistemas socioeconômicos, os ecossistemas, sistemas urbanos, sistemas hidrológicos e etc.

Os sistemas hidrológicos abrangem todas as relações com envolvimento da água, mas de uma maneira mais sucinta os principais sistemas hidrológicos são os de águas superficiais e subterrâneas. Em águas superficiais, existem os sistema hidrológicos lênticos, que relativamente possuem poucas pesquisas, a valoração nesse meio é baseada na limnologia. 
Partindo desses pressupostos, esse artigo tem como objetivo expor definições e diferenciações sucintas sobre sistemas hidrológicos lênticos naturais, tomando como base a pobre literatura que atualmente existe sobre o assunto.

\section{DESENVOLVIMENTO}

Um geógrafo usa-se de modelos como um instrumento de trabalho que deve ser utilizado na análise dos sistemas das organizações espaciais. A construção de modelos pode ser ponderada como estruturação sequencial de ideias relacionadas com a composição sistêmica. A compreensão da definição do objeto de estudo consente estruturar o funcionamento do sistema, a fim de torná-lo compreensível e expressar as relações entre os seus múltiplos componentes. (CHRISTOFOLETTI, 1985 apud FRANCO, 2011)).

De acordo com Esteves (1998) sistemas hidrológicos lênticos não são elementos permanentes da paisagem da terra, pois eles são fenômenos de curta durabilidade na escala geológica, portanto surgem e desaparecem no decorrer do tempo, sendo influenciados por quatro dimensões: Região litorânea, Região Limnética ou pelágica, Região profunda e interação água/ar. São diferenciados em três tipos lagos, lagoas e charcos. Podendo ser um sistema hídrico em perímetro rural e/ou urbano.

A diferenciação entre os tipos de formações lênticas ainda é confusa e não possui estudos específicos. Um lago, Figura 2A, tem sua definição na geologia, são massas de água parada ou levemente corrente com uma área limnológica superior a $100.000 \mathrm{~m}^{2}$. A lagoa, Figura 2B, é definida como massas de água parada ou de corrente reduzida com área limnológica inferior a $100.000 \mathrm{~m}^{2}$. E, o charco, Figura 2C, são massas de água parada ou de corrente muito reduzida de carácter temporário. Porém, essas definições podem variar de país para país. 
Figura 2: (A) llustração de um lago. (B) llustração de uma lagoa. (C) llustração de um charco.

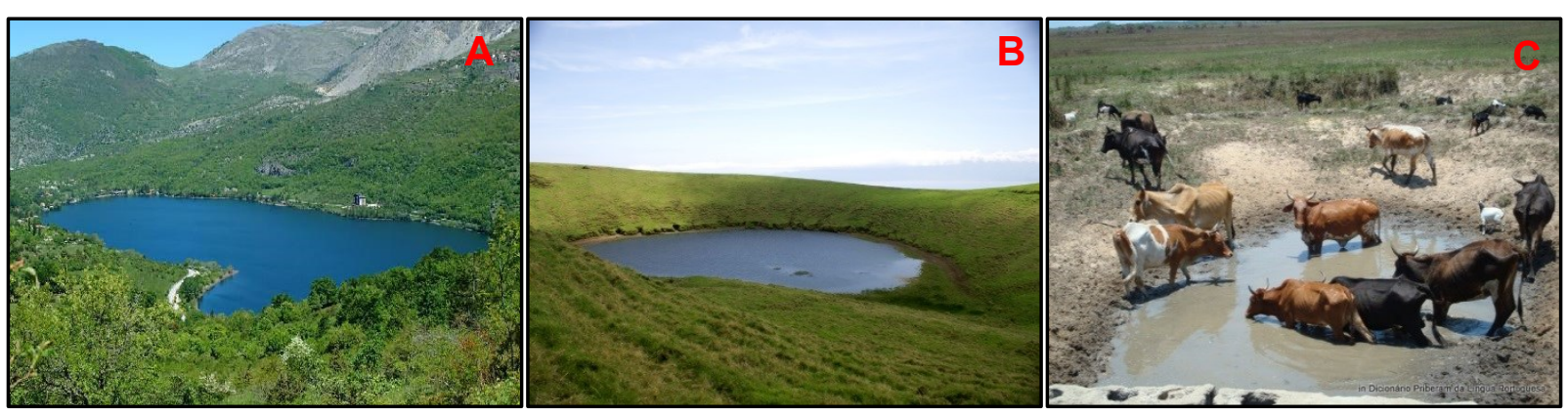

Para Esteves (1998) os lirnnólogos encontram muita dificuldade para diferenciar um lago de uma lagoa. Partindo de outro conceito para esta diferenciação, pode-se tomar a profundidade da bacia lacustre e a profundidade que alcança a região iluminada na coluna d' água. Como lagoa, pode-se considerar os corpos d' água rasos, de água doce, salobra ou salgada, em que a radiação solar pode alcançar o sedimento, possibilitando, consequentemente, o crescimento de macrófitas aquáticas em toda a sua extensão.

Figura 3: Conceito de diferenciação baseado na profundidade de penetração da radiação solar.

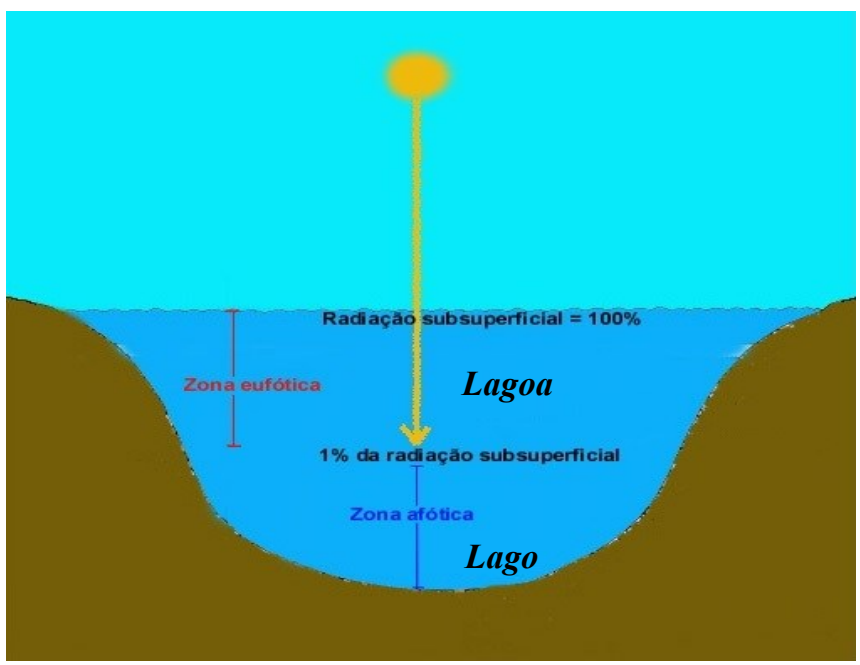

Fonte: adaptado do Laboratório de Limnologia e Planejamento Ambiental (UFES). 
A principal característica de um sistema lêntico é a alta capacidade para solubilização de compostos orgânicos, gradientes verticais, baixo teor de sais dissolvidos, alta densidade e viscosidade da água, capacidade de sedimentação, seixos internos, a temperatura e radiação subaquática (ESTEVES, 1998).

Um conceito que define as diferenças dos sistemas hidrológicos lênticos rurais e urbanos para homem possivelmente está ligado ao seu destino. Primeiramente, é a localização a principal diferença de uma lagoa em zona rural e outra em zona urbana, mas a maneira de the dar com o recurso diferem-nas. A população rural usa-se da extração da água para fins de abastecimento pessoal e bebedouro aos animais. Entretanto, a população urbana tem em sua visão a harmonia paisagística, completando um ambiente antrópico com um meio natural preservado ou não.

A urbanização aos arredores de corpos lênticos nasceram por questões de uma melhor sobrevivência para o ser humano. A necessidade de água para o consumo propiciou a instalação de povoados as margens de rios e lagos/as. A partir de então, o crescimento histórico da sociedade transformaram a arquitetura e aglomeração das cidades.

A engenharia revolucionou o abastecimento de água através da extração em aquíferos e rios mais distantes, ligando-os com galerias para servir a população. Com isso, a utilização de lagos e lagoas para abastecer as cidades tornou-se desnecessária. Nasce então, o conceito de um ambiente para harmonia paisagística natural dentro das cidades.

Muitos corpos lênticos receberam a ideia da preservação de sua natureza, propiciando uma visão mais racional do ambiente. Não obstante, a atuação da engenharia e arquitetura também estiveram presentes nesses meios, criando lagos artificiais ou alterando sua forma original, Figura 4. 
Figura 20: (A) Lago Meixi em Chansgsha, China. (B) Lagoa Solon de Lucena em João Pessoa/PB, Brasil. (C) Lago do Central Parque em Nova lorque, EUA.

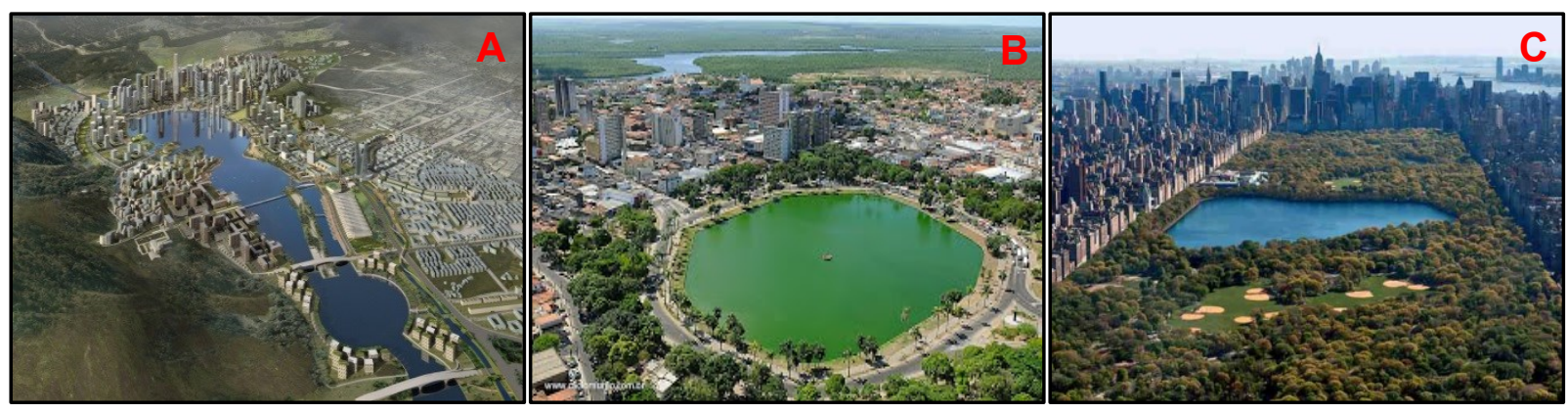

\section{CONCLUSÃO}

Os sistemas hidrológicos lênticos naturais em suas classificações: lagos, lagoas e charcos; mostraram ainda um certo déficit com exatidão em suas definições. A geologia trabalho com um aspecto, que não é tão aceitado; Esteves mostra outra definição sem uma abordagem aprofundada.

A renovação de novas metodologias e resultados mais intensos e com exatidão faz-se importante para a literatura do país. Isso proporciona a leigos e interessados no assunto um conhecimento fácil e resulta em trabalhos mais coerentes e concisos, com isso o ganho acadêmico é exaltado.

\section{REFERÊNCIAS}

CHIAVENATO, I. Introdução a teoria geral da administração . $7^{\text {a }}$ Ed. São Paulo/SP: Campus, 2004.

CHRISTOFOLLETTI, A. A teoria dos sistemas In: Boletim de Geografia Teorética, 1 (2) p.43-60. 1979.

1999. 236p

Modelagem de Sistemas Ambientais. $1^{\text {a }}$ edição. São Paulo: Edgard Blucher,

ESTEVES, F. A. Fundamentos de Limnologia. Revista Interciência. Rio de Janeiro, 1998.

FRANCO, J. R. C. Os Lagos como Expressão Geomorfológica da Paisagem na Baixada Maranhense, Brasil. II Colóquio Internacional Desenvolvimento Local e Sustentabilidade: Novas abordagens velhos dilemas. São Luís/MA, 2011.

IZIPPATO. F. J. Diretrizes para análise ambiental com uso de geotecnologias na Bacia Hidrográfica do Córrego do Pinto, Três Lagoas/MS. Dissertação de Mestrado em Geografia. UFMS: Três Lagoas/MS, 2013. 161p. 